\section{P-212 EVERYTHING IN PLACE: A GOOD DEATH IS A WELL-PLANNED DEATH}

Louise Johnson. St. Cuthbert's Hospice, Durham, UK

\subsection{6/bmjspcare-2016-001245.233}

Increasingly individuals are preferring to die at home, eliciting an increased need for good communication, forward planning is more crucial than ever. We need to be better equipped for difficult conversations and more confident in sharing our wishes with others.

The 'Everything in Place' project raises the profile of these taboo subjects, reducing barriers by encouraging conversations and advocates the need to take responsibility for informed decision making. Six sessions included:

- The last taboo

- Wills

- Powers of Attorney

- Advance decisions for health and care

- Funeral planning/poverty

- A strong soul/organ donation.

The project is delivered through local community centres, housing organisations, workplaces and communities of interest. Initially presentations were made to gauge interest, dispel myths, and demonstrate the mass of practical evidence surrounding what constitutes a good death. Once venues were established the project was promoted through posters, leaflets, newspaper and radio, a work book was designed to help with decision making and record thoughts and plans.

Six sessions were delivered in five venues (monthly), five people attended during week one and overall we delivered the equivalent of 82 individual sessions, results below:

\begin{tabular}{llll}
\hline As a result of this project : & Yes & No & Not sure \\
\hline Have your views on death changed? & 7 & 2 & 1 \\
Are you more comfortable talking about death? & 9 & 1 \\
Are you more comfortable thinking about your own death? & 9 & 1 \\
Are you more able to plan for your own death? & 6 & 4 \\
Are you more confident about availability of home care? & 5 & 5 \\
Were the activities relevant to your own family? & 10 & \\
Would you recommend the sessions to others? & 10 & \\
\hline
\end{tabular}

Attendance rates might suggest the uncomfortable nature of death, however results would confirm that in the main discussions were beneficial. We believe the project is making an impact and continue our work to make this information accessible.

\section{P-213 DEVELOPING A PALLIATIVE HUB: LESSONS FROM THE ISLAND OF IRELAND}

Karen Charnley, Gareth Wescott, Cathy Payne. All Ireland Institute of Hospice and Palliative Care, Dublin, Ireland

\subsection{6/bmjspcare-2016-001245.234}

Background Meeting the information needs of entire community including patients, families, carers, health and social care professionals and researchers is important in a society where online resources are an increasing source of information. Providing this information digitally in one location will reduce the burden on individuals trying to navigate the internet and multiple sources of information, which may not be appropriate or relevant.

Aim To develop the Palliative Hub, as a gateway for information, education and guidance regarding palliative care.

Method Drawing on the skills and expertise of a range of stakeholders, working groups were established, which represented service users, carers, providers, charities and advocacy groups. The purpose of these groups was to assist with the design and development of the Palliative Hub, as sites to provide information, education and guidance about palliative care. The Palliative Hub whilst providing information also acts to filter and direct the user to the most relevant sources of further information.

Results It is anticipated that this resource will assist with meeting the palliative care information and education needs of the entire community in one place with key signposts to relevant sources and resources.

Conclusion The Palliative Hub has the potential to become an integral element in meeting the palliative care information and education needs of the entire community and is an example of an innovative and collaborative project across the island of Ireland, which could be translated across other jurisdictions.

\section{P-214 TERMINOLOGY RESEARCH - THE WORDS WE USE TO DESCRIBE OUR CARE}

Tony Carpenter. Phyllis Tuckwell Hospice Care, Farnham, UK

\subsection{6/bmjspcare-2016-001245.235}

Background There was uncertainty over the words to use to describe the care we provide and type of patients we support, particularly following the transfer of an NHS service to our hospice management in 2015. Other hospices use inconsistent language, so there was no clear direction to follow to create our own language.

Aim In March 2016, we undertook some research to enable us to understand the best phrases to use with supporters, the general public and patients/relatives.

Methods Quantitative research using an online survey was undertaken with 533 supporters and general public; qualitative research through six discussion groups was undertaken with staff, volunteers, patients, carers, supporters and general public; and telephone interviews with seven local GPs.

Results "Illness" was preferred as descriptor, over others like "condition" or "disease".

'Terminal illness' was established as the best phrase for those receiving hospice care and chosen equally by both supporters and general public, but should be softened by saying "living with a terminal illness" to make it more positive and hopeful.

Rejected words: Life-limiting, Life-changing, Incurable, Serious Progressive, Advanced.

'Hospice care' is used our name, so does not to be in the descriptor of the type of care. On its own it can suggest that we only provide care in a hospice building, for in-patients only.

'End of life care' was established as the best phrase to describe type of care, as it was safe, specialised, supportive and inclusive, but we should also include 'Supportive Care', as it suggests that the family are supported as well as the patient, and we also provide non-physical care for the patient. 
Rejected words: Palliative, Holistic, Specialist, Rehabilitative, Care in the last days

Conclusion Phyllis Tuckwell Hospice Care provides supportive and end of life care for patients and families living with a terminal illness.

\section{P-215 PATIENTS' UNDERSTANDING OF TERMINOLOGY USED IN PALLIATIVE CARE SERVICES}

${ }^{1}$ Abi Ponnampalam, ${ }^{2}$ Nicola Holtom, ${ }^{2}$ Sanda Hlaing. ' Garden House Hospice, Letchworth Garden City, UK; ${ }^{2}$ Norfolk and Norwich University Hospital, Norwich, UK

\subsection{6/bmjspcare-2016-001245.236}

Background Good communication stipulates that we avoid using jargon. However patients' understanding of terms such as 'specialist palliative care nurse' and 'Macmillan nurse' seems variable. We are often asked by patients who are already known to a palliative care specialist nurse, whether they could also see a Macmillan nurse.

In addition, as palliative care evolves and the role of hospices has changed to include complex symptom control, the subsequent name change to 'Specialist Palliative Care Unit' seems logical. However patients' understanding of this seems variable.

Aim To establish the understanding patients have of the terms commonly used in palliative care and ascertain whether the terms we take for granted cause any confusion.

Methods Qualitative semi structured interviews with 20 participants attending palliative care outpatient clinics. Participants had a range of life-limiting conditions and prognoses. Patients new to the service and those already known were sampled to identify any difference in their understanding. Interviews were recorded and transcripts were analysed using the principles of thematic analysis.

Results Only four patients were able to identify that the roles of specialist palliative care nurses (SPCN) and Macmillan Nurses were similar. Four patients felt that the SPCN was the same as the cancer specialist nurse. Five patients specifically mentioned the Macmillan nurse being available to provide hands on basic nursing and overnight care.

All participants identified end-of-life care with the term hospice. More than half did not know what a Specialist Palliative Care Unit entailed. Almost a third thought it was the same as the acute oncology ward or chemo/radiotherapy unit. Only three patients expressed their understanding of the two providing a similar role.

Conclusion There seems to be a real discrepancy between what is meant by these terms used commonly in practice and what is actually understood by patients. This raises serious issues which would benefit from further study

\section{P-216 INTERVAL}

Steven Eastwood, Peter Gilliam. Earl Mountbatten Hospice, Newport, UK

\subsection{6/bmjspcare-2016-001245.237}

Introduction Non-fiction filming involving death and dying has taboo status in terms of what western society can and cannot sanction. Made over the course of 12 months through close engagement with individuals experiencing and witnessing death and dying, our film consists of long sequences showing the people, environments and activities in and around the hospice, exploring what happens at the end of a person's life.

The project Upon filming it became clear that the hospice acts as the beating heart at the centre of the island, with its community team operating as an artery system, extending out to every part of the land. In many ways this is a palliative island, a place where dying is visible. With this notion of an island as ecology, one that is familiar with end of life, the filmmaker began to notice complex and coexistent movements and practices associated with dying. Filming with people in family homes and on the ward during the last weeks of life unfolded to include the very intimate moment of the instant of death. Filming also extended out into the landscape, taking in chemotherapy, bereavement seminars, pathology lab activity, but also ferry crossings, druid death ceremonies, and palliative care given to ageing big cats at the zoo.

The project attempts to engender a space where the phenomenon and phenomena of dying and death can be given an image. This reflects changing attitudes in palliative care and society around the visibility of death and dying. Navigating this difficult ethical territory involved adopting a way of seeing, and being with, the terminally ill person that has some confederacy with the practices of the palliative care professional. What emerges is a slow cinema description of the temporality of dying, an image of care and attentiveness and the very natural process of death.

\section{P-217 COMMUNICATION PASSPORT PROJECT}

${ }^{1}$ Ruth Butcher, ${ }^{1}$ Leanna Tuffin, ${ }^{1}$ Natasha Harding, ${ }^{1}$ Liz Lewington, ${ }^{2}$ Sophie Dziwinski. ${ }^{1} J e s s i e$ May, Bristol, Great Britain; ${ }^{2}$ Roald Dahl; ${ }^{3}$ Burdett Trust

\subsection{6/bmjspcare-2016-001245.238}

Jessie May is a charity-run organisation who provides specialist care and support through a team of children's nurses and nursery nurses in partnership with families and other agencies to deliver respite and palliative care service in the comfort of the families own home to children and young people with life limiting conditions.

The Departments of Health and Education (2015) define children with complex and continuing health care needs as individuals with prolonged chronic conditions which have an adverse effect upon a child's development and welfare. Many of the children with long term life-limiting illness or disabilities may have impaired communication (Teare, 2009).

However Hewitt-Taylor (2008) suggests that communication difficulties may not arise because of the child's inability to understand, but occurs through inability to make themselves understood by others. Children with complex needs communicate about the same things as the other children, for example their feelings, needs, likes and dislikes (Mencap, 2010). The Convention on the Rights of a Child (2014), specifically states that each and every child has a right to be listened to. Jessie May has recognised the possible barriers for some of the children that we care for being heard and listened to due to communication barriers. This problem is something that communication passports address.

A literature review identified three pieces of research, Millar (2007), Sanderson (2003) and Bell, 2012), all have similar findings that suggest there are significant benefits to using communication passports, and we aim to conduct a study on communication passports to ensure that we produce a passport that is relevant to the service that we provide. 